\title{
Vitamin K antagonist embryofetopathy
}

INSERM

\section{Source}

INSERM. (1999). Orphanet: an online rare disease and orphan drug data base. Vitamin K antagonist embryofetopathy. ORPHA:1914

Vitamin $\mathrm{K}$ antagonist embryofetopathy is characterized by a group of symptoms that may be observed in a fetus or newborn when the mother has taken oral vitamin $\mathrm{K}$ antagonists, such as warfarin during pregnancy. Vitamin $\mathrm{K}$ antagonists are anticoagulant drugs that provide efficient thromboprophylaxis and that can cross the placenta. 5-12\% of infants exposed to warfarin between 6-9 weeks gestation present nasal hypoplasia and skeletal abnormalities, including short limbs and digits (brachydactyly), and stippled epiphyses. Warfarin fetopathy with central nervous system abnormalities (hydrocephalus, intellectual disability, spasticity, and hypotonia) or ocular abnormalities (microphthalmia, cataract, optic atrophy), fetal loss, and stillbirth, occurs in infants exposed at later gestations. Additional features that have been reported after in utero warfarin exposure include facial dysmorphism (cleft lip and/or palate, malformed ears), choanal atresia or stenosis, aorta coarctation, situs inversus totalis, bilobed lungs, and ventral midline dysplasia. 